\title{
Visible light-induced photochemical fabrication of ultrathin Ag nanoparticles decorated PPy nanosheets and its oxygen reduction activity
}

\author{
Juan Du ${ }^{1}$, Shiming Meng ${ }^{1,2, *}$, Mei Y $u^{1}$, Jianhua Liu ${ }^{1}$, Songmei $\mathrm{Li}^{1}$ \\ ${ }^{1}$ School of Materials Science and Engineering, Beihang University, Beijing 100191, China \\ ${ }^{2}$ School of Aeronautic Science and Engineering, Beihang University, Beijing 100191, China \\ *E-mail: mengshm@buaa.edu.cn
}

doi: $10.20964 / 2021.04 .42$

Received: 22 October 2020 / Accepted: 6 January 2021 / Published: 28 February 2021

\begin{abstract}
In this work, $\mathrm{Ag}$ nanoparticles decorated Polypyrrole (PPy) nanosheets were synthesized on the surface of $\mathrm{Ag}_{3} \mathrm{PO}_{4}$ nanoparticles (APNPs) by a visible light-induced photochemical method in a simple pyrrole solution. Independent Ag nanoparticles decorated PPy nanosheets (UAPNs) was obtained after nitric acid dissolution and sonication. The APNPs were used as visible-light photocatalyst, templates and silver source in the preparation process. The morphology, structure and composition of the resulting hybrid materials were characterized by a variety of characterization methods, which demonstrated that the photoreduced Ag nanoparticles were uniformly deposited in the photooxidized PPy nanosheets through this APNPs based visible light-induced photochemical method, forming the microsized UAPNs with a thickness less than $10 \mathrm{~nm}$. The resulting UAPNs show a good electrocatalytic activity for oxygen reduction reaction (ORR) in alkaline solution.
\end{abstract}

Keywords: Ag nanoparticles; polyptrrole; photochemical; nanosheets; oxygen reduction reaction

\section{$\underline{\text { FULL TEXT }}$}

(C) 2021 The Authors. Published by ESG (www.electrochemsci.org). This article is an open access article distributed under the terms and conditions of the Creative Commons Attribution license (http://creativecommons.org/licenses/by/4.0/). 